MRS Advances (C) 2018 Materials Research Society

DOI: 10.1557/adv.2018.163

\title{
Application of Low-Cost Cu-Sn Bimetal Alloy as Oxygen Reduction Reaction Catalyst for Improving Performance of the Microbial Fuel Cell
}

\author{
Md. T Noori ${ }^{1}$, Gaurav Dhar Bhowmick ${ }^{1}$, Bikash R Tiwari ${ }^{2}$, M.M. Ghangrekar ${ }^{2}$ and C.K. \\ Mukhrejee $^{1}$ \\ ${ }^{I}$ Department of Agricultural and Food Engineering, Indian Institute of Technology, Kharagpur, \\ Kharagpur - 721302 \\ ${ }^{2}$ Department of Civil Engineering Indian Institute of Technology, Kharagpur, Kharagpur - 721302
}

ABSTRACT

In this experiment, a new bimetal low-cost $\mathrm{Cu}-\mathrm{Sn}$ alloy was synthesized and it was tested as catalyst for oxygen reduction reaction (ORR) in MFC and the results were compared with the commercially available Pt-C catalyst. Cyclic voltammetry for evaluating ORR of the test cathode containing $\mathrm{Cu}$-Sn catalysts under oxygen saturated environment displayed large ORR current peak, showing less overpotential demand for ORR. Maximum power density of 457 $\mathrm{mW} / \mathrm{m}^{2}$ obtained from MFC using Cu-Sn catalyst, was found to be slightly higher than the power density of $446 \mathrm{~mW} / \mathrm{m}^{2}$ demonstrated by MFC using Pt based cathode. Biochemical conversion of organic matter to direct electric current in $\mathrm{Cu}-\mathrm{Sn}$ based MFC occurred at a coulombic efficiency of $55.8 \%$, while demonstrating $92 \%$ of chemical oxygen demand removal. This study demonstrated application of low cost $\mathrm{Cu}-\mathrm{Sn}$ bimetal alloy as excellent ORR catalyst in MFC and would be very helpful to commission larger MFCs for field applications to harvest energy in the form of direct electricity from wastewaters while offering wastewater treatment.

Introduction

Microbial fuel cell (MFC) is a bifunctional bio-electrochemical device, which is capable of treating wastewater along with bioenergy recovery in terms of electricity by taking advantage of bacterial metabolic activity [1]. Performance of MFC depends on redox reaction kinetics occurring on anode and cathode. Cathodic reduction kinetics, in which oxygen reduction reaction (ORR) is mostly preferred, is considered as key influencing parameter in the performance of MFCs. The ORR under natural condition using carbon based electrodes is sluggish in nature due to high overpotential demand, which eventually reduces the voltage or current output from MFCs. Consequently, the ORR consumes larger amount of energy to push the reaction forward. A presence of catalyst can reduce the overpotential on cathode. Among various remarkable ORR catalysts developed recently, for instance $\mathrm{MnO}_{2}$ [2], $\mathrm{V}_{2} \mathrm{O}_{5}$ [3], N-type $\mathrm{Cu}_{2} \mathrm{O}$ [4], NiPc [5] etc., metal alloys have proven to be superior due to d-band electron sharing ability and improved geometrical shape [6]. Yan et al. [7] synthesized $\mathrm{Pt}_{3} \mathrm{Fe}$ alloy to be used as ORR catalyst and the results showed $18 \%$ improvement in power from $1.44 \mathrm{~W} / \mathrm{m}^{2}$ in MFC 
using Pt as catalyst to $1.68 \mathrm{~W} / \mathrm{m}^{2}$ in MFC with $\mathrm{Pt}_{3} \mathrm{Fe}$ alloy. The Pt-Ni alloy catalysed cathode also offered substantial improvement in power recovery from MFC $\left(0.63 \mathrm{~W} / \mathrm{m}^{2}\right)$ as compared to the MFC using Pt catalyst $\left(0.43 \mathrm{~W} / \mathrm{m}^{2}\right)$ [8]. In terms of performance, these alloys indeed have noteworthy competencies, but high commercial cost and acute poisoning effect confines their extensive use in MFCs. In order to address these shortcomings, Venkatesan and Dharmalingam, [9], doped $\mathrm{Pt}$ in $\mathrm{TiO}_{2}$ framework and used as ORR catalyst. The performance of MFC using this cathode however enhanced as compared to $\mathrm{Pt}$ alone $\left(110 \mathrm{~mW} / \mathrm{m}^{2}\right.$ vs. $77 \mathrm{~mW} / \mathrm{m}^{2}$, respectively), but as compared to above mentioned results, these power densities are still lower. Therefore, more precise and comprehensive efforts are required to address the low power recovery issue from MFCs fabricated using low cost catalyst.

In this study, a low-cost Cu-Sn alloy was synthesized using sequence of controlled heat reduction method and employed as cathode catalyst in MFCs to improve the ORR and thus power recovery. As-synthesized $\mathrm{Cu}-\mathrm{Sn}$ alloy was analyzed in X-ray diffraction and scanning electron microscopy to identify its exact phase orientation and morphology, respectively. Extensive examination of ORR kinetics of cathode was performed with the help of cyclic voltammetry and electrochemical impedance spectroscopy. Finally, real-time application of this catalyst was assessed by using in MFC and performance was evaluated in terms of power output, coulombic efficiency and wastewater treatment. Performance of this MFC was compared with the MFC using Pt$\mathrm{C}$ as cathode catalyst.

\section{Materials and methods}

\section{Synthesis and characterization of $\mathrm{Cu}-\mathrm{Sn}$ alloy}

Bimetallic alloy of $\mathrm{Cu}-\mathrm{Sn}$ was synthesized using sequential thermal reduction method. In a conical flask, 1-octadecene (ODE) and oleic acid (OAC), with volumetric ratio of $15: 1 \mathrm{ml}$, was mixed and heat treated at $120^{\circ} \mathrm{C}$ for $30 \mathrm{~min}$, followed by heating at $260{ }^{\circ} \mathrm{C}$ for $10 \mathrm{~min}$ and then $6 \mathrm{ml}$ of oleylamine was added. A separate solution of $0.04 \mathrm{~g}$ of Copper (II) acetylacetonate and $0.1 \mathrm{~g}$ Tin (II) acetylacetonate was prepared in $5 \mathrm{ml}$ benzyl ether under ultrasonication. This copper solution was added to the above heated solution and the temperature was gradually increased at the rate of $2{ }^{\circ} \mathrm{C} / \mathrm{min}$ up to $310^{\circ} \mathrm{C}$. The final temperature was upheld for $1 \mathrm{~h}$ until the colour of the solution became reddish brown to greyish black, this change in colour confirmed the formation of $\mathrm{Cu}-\mathrm{Sn}$ alloy. The alloy recovered by ultrafiltration and washed several times with ethanol for enhancing the purity. Final product was dried in vacuum oven overnight and stored in air-tight desiccator. Morphology of $\mathrm{Cu}-\mathrm{Sn}$ alloy was visually examined using field emission scanning electron microscopy (FESEM, Merlin-Zeiss, Germany); whereas the crystallographic phase and orientation was identified using X-ray diffraction technique under $\mathrm{Cu}-\mathrm{K} \alpha$ irradiation $(\lambda=0.1541 \mathrm{~nm})$ (PanAnalytical, The Netherlands). The XRD patterns were collected in $2 \theta$ value ranging from $10^{\circ}$ to $90^{\circ}$ at a scanning rate of $0.12^{\circ} \mathrm{s}^{-1}$.

\section{MFC setup, operation and analytical procedures}

Single-chambered test MFCs were fabricated using plexiglass having anodic chamber volume of $60 \mathrm{ml}$ and operated as reported earlier [10]. Carbon felt having projected surface area of $9 \mathrm{~cm}^{2}$ was used as anode in all the MFCs. The air-cathodes were fabricated either of $\mathrm{Cu}-\mathrm{Sn} /$ carbon black (C) (1:1) or Pt-C catalyst or only carbon felt without any catalyst for comparative study. A loading of $2 \mathrm{mg} / \mathrm{cm}^{2}$ of $\mathrm{Cu}-\mathrm{Sn} / \mathrm{C}$ and 1 
$\mathrm{mg} / \mathrm{cm}^{2}$ of Pt-C was maintained on the cathode. Detailed fabrication process is reported earlier [3]. Nafion 117 was used as proton exchange membrane (PEM) in MFCs. Both anode and cathode were carefully positioned either side of the PEM and the electrode assembly was placed in the MFC main block by facing the cathode on air-side and anode at liquid chamber. Epoxy glue was applied to make the MFC water tight.

Electrochemical ORR in presence of $\mathrm{Cu}-\mathrm{Sn}$ was evaluated using cyclic voltammetry (CV) and electrochemical impedance spectroscopy (EIS) in 3-electrode electrochemical cell under $\mathrm{O}_{2} / \mathrm{N}_{2}$ saturated $1 \mathrm{~N} \mathrm{KCl}$ solution. $\mathrm{Cu}-\mathrm{Sn}$ catalyzed cathode served as working electrode and a Pt wire was used as counter electrode. The voltages were applied with respect to $\mathrm{Ag} / \mathrm{AgCl}$ reference electrode. The potential widow for $\mathrm{CV}$ adopted was $0.99 \mathrm{~V}$ to $-0.99 \mathrm{~V}$ and the scan rate was varied from $5 \mathrm{mV} / \mathrm{s}$ to $100 \mathrm{mV} / \mathrm{s}$. EIS was performed under alternating current frequency ranging from $100 \mathrm{kHz}$ to 100 $\mathrm{mHz}$ with voltage amplitude of $10 \mathrm{mV}$. Maximum attainable power density was calculated by polarization study performed with varying external resistance from 10000 $\Omega$ to $10 \Omega$. Coulombic efficiency was calculated as reported in literature [1]. Chemical oxygen demand (COD) estimation was performed using close refluxed method as suggested by APHA, [11].

\section{Results and discussion}

\section{Characterization of $\mathrm{Cu}-\mathrm{Sn}$ and $\mathrm{ORR}$ performance}

The surface morphology as shown in FESEM micrograph reveals successful growth of spherical $\mathrm{Cu}$-Sn nanoparticles having diameter of few hundred nanometer (Figure 1a); thus having high surface area to volume ratio, which is helpful for enhancing the ORR. The crystal orientation and phase identification was performed using XRD and the major diffraction peaks appeared at $2 \theta=42.38^{\circ}, 48.9^{\circ}, 61.9^{\circ}, 72.6^{\circ}, 78.4^{\circ}$ and $88.2^{\circ}$ are perfectly matching to the tetragonal crystal symmetry of $\mathrm{Cu}_{5.6} \mathrm{Sn}$ alloy (\#JCPDS card $31-0487)$. The reference peaks corresponding to the $2 \theta$ value along with XRD pattern of original sample is bestowed in the Fig. 1b. In addition to the desired alloy, few more diffraction peaks at $2 \theta=43.2^{\circ}, 50.4^{\circ}$ and $74.1^{\circ}$ were noticeable, which can be indexed as cubic symmetry of pure $\mathrm{Cu}$ element (\#JCPDS card 04-0836). The presence of $\mathrm{Cu}$ element can be attributed to the early formation of $\mathrm{Cu}$ during the thermal reduction as the $\mathrm{Cu}^{2+}$ has high positive reduction potential of $0.34 \mathrm{~V}$ [12]. In addition, possibility of SnO formation was also analysed; the reference peak positions as shown in the Figure 1b, for pure SnO tetragonal symmetry (\#JCPDS card 072-1012) did not match with the XRD pattern of as-synthesised material, confirming absence $\mathrm{SnO}$ in the material. The XRD results confirmed the nucleation of $\mathrm{Cu}$ and $\mathrm{Sn}$ to form $\mathrm{Cu}_{5.6} \mathrm{Sn}$ alloy.
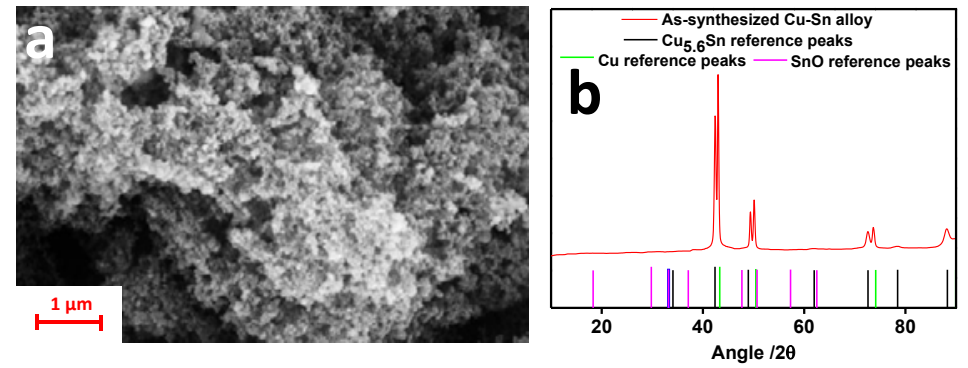

Figure 1. (a) SEM micrograph and (b) XRD pattern of as-synthesized Cu-Sn alloy. 
The ORR potential of Cu-Sn employed cathode was tested using CV and EIS analysis under $\mathrm{O}_{2}$ or $\mathrm{N}_{2}$ saturated electrolyte. Under $\mathrm{O}_{2}$ saturated condition, the $\mathrm{CV}$ voltammogram demonstrated couple large redox current peaks, which became shortened under $\mathrm{N}_{2}$ saturated environment revealing $\mathrm{O}_{2}$ as a sole terminal electron acceptor (TEA) responsible for completing the redox cycle (Figure 2a). However, the redox peaks under $\mathrm{N}_{2}$ saturated environment could not be completely vanished from CV voltammogram, possibly due to force diffusion of $\mathrm{O}_{2}$ in the system from the environment. In addition, the ratios of currents in the redox couples were found almost equal to 1 , which indicates to happen a perfect reversible reaction and therefore $\mathrm{Cu}-\mathrm{Sn}$ catalyst could be used for longer period of time. Under $\mathrm{O}_{2}$ saturated condition, the $\mathrm{CV}$ analysis was further extended by varying the scan rate to have better understanding on the reversibility of the reaction.
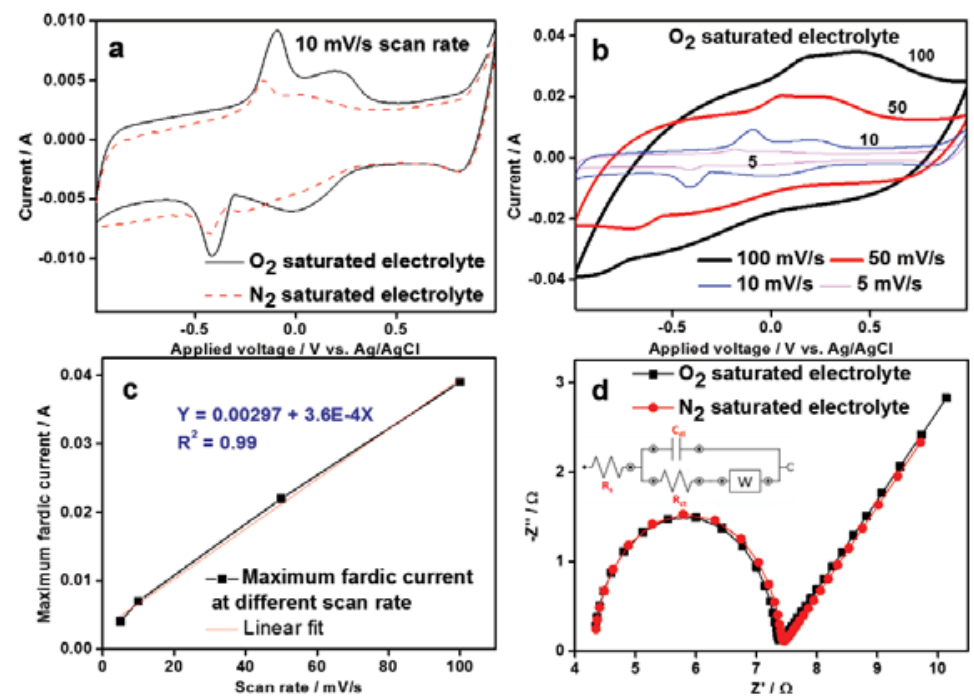

Figure 2. Electrochemical kinetics of ORR of $\mathrm{Cu}-\mathrm{Sn}$ catalysed cathode (a) $\mathrm{CV}$ curve under $\mathrm{O}_{2} / \mathrm{N}_{2}$ saturate electrolyte (b) CV curve under different scan rates (c) Maximum Faradic current at different scan rates and (d) EIS spectra.

As shown in Figure $2 b$, the current response was noted to be enhanced proportionally by increasing the scan rate from $5 \mathrm{mV} / \mathrm{s}$ to $100 \mathrm{mV} / \mathrm{s}$ and the maximum faradic current response obtained in reduction cycle was found to be linear (Figure 2c), which further confirms the reversibility of the reaction. Current response of the cathode at $100 \mathrm{mV} / \mathrm{s}$ was monitored for 2500 cycles to check its stability. Fig. S1 clearly shows no depletion in current response during the time frame of 2500 cycles of $\mathrm{CV}$ and the shape of the voltammogram was noted intact, which reveals longevity of the catalyst to carry out ORR. The interfacial charge transport behavior was investigated by EIS and the charge transfer resistance values of $2.99 \Omega$ and $3.05 \Omega$ were found almost similar in $\mathrm{O}_{2}$ and $\mathrm{N}_{2}$ saturated conditions, thus confirming the electrode property did not change 
(Figure 2d). Similarly, the solution resistance of around $4 \Omega$ was observed in the both cases, which is obvious due to similarity of the electrolyte.

\section{Power generation and wastewater treatment}

The close circuit voltages i.e. under $100 \Omega$ external resistance in both MFCs were found in increasing order as the operation day progressed and reached at stable value of $161 \pm 6 \mathrm{mV}$ in MFC-1 (having $\mathrm{Cu}$-Sn catalysed cathode) and $147 \pm 9 \mathrm{mV}$ in MFC-2 (having Pt-C catalysed cathode) corresponding to the sustainable power density of $415 \pm 31 \mathrm{~mW} / \mathrm{m}^{2}$ and $347 \pm 42 \mathrm{~mW} / \mathrm{m}^{2}$, respectively, after two sequential feed batch cycle of operation. Maximum power recovery and different overpotential losses were estimated by polarization study, which was carried out when the output voltage showed minimum deviation between consecutive feed cycles. A typical polarization curve of this study is shown in Figure 3a, which demonstrate a maximum power density of 456 $\mathrm{mW} / \mathrm{m}^{2}$ for MFC-1 and $446 \mathrm{~mW} / \mathrm{m}^{2}$ for MFC-2. Higher sustainable power in MFC-1 having $\mathrm{Cu}-\mathrm{Sn}$ cathode catalyst as compared to $\mathrm{Pt} / \mathrm{C}$ (MFC-2) could be attributed to its excellent ORR activity, owing to the distinctive electron d-band sharing feature of alloy and structural integrity. For example, MFC using single metal based $\mathrm{Pt}-\mathrm{C}$ could produce significantly less power density of $70.1 \pm 1.2 \mathrm{~mW} / \mathrm{m}^{2}$ as compared to the power density of $83.2 \pm 2.9,88.4 \pm 1.4$ and $88.4 \pm 1.4 \mathrm{~mW} / \mathrm{m}^{2}$, respectively, obtained from MFC using $\mathrm{Pt}-\mathrm{Ni} / \mathrm{C}, \mathrm{Pt}-\mathrm{Co} / \mathrm{C}$ and $\mathrm{Pt}-\mathrm{Fe} / \mathrm{C}$ alloy as catalyst on cathode (Chang et al., 2014). Moreover, MFC-1 showed little higher activation overpotential as compared to MFC-2, since the voltage drop was observed rapid at higher values of external resistance. However, at concentration overpotential range (at lower value of external resistances), the voltage drop was found lower in MFC-1 when compared with MFC-2, revealing less concentration overpotential for diffusion of $\mathrm{O}_{2}$ to the reaction interface. The ohmic overpotential was also recorded low in MFC-1 as compared to MFC-2, which further could identify by estimating internal resistances (160 $\Omega$ vs. $185 \Omega$, respectively). In addition, the specific power production cost was calculated to be $16 \mathrm{~mW} / \mathrm{\$}$ for MFC-1 as compared to the cost of $0.48 \mathrm{~mW} / \$$ for MFC-2. Therefore it can be concluded that the synthesized $\mathrm{Cu}-\mathrm{Sn}$ has all the potential abilities to replace Pt-C as cathode catalyst in future MFCs.

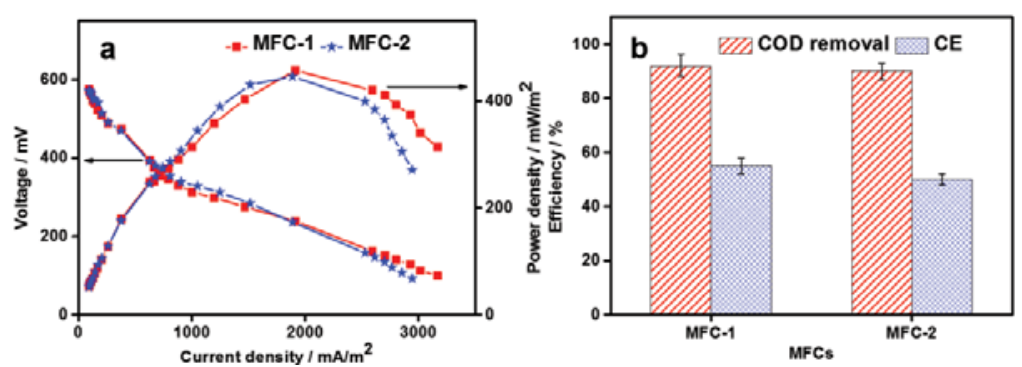

Figure 3. (a) Polarization plot (b) wastewater treatment and coulombic efficiency.

MFCs are considered as bifunctional device as these can treat numerous kinds of wastewater along with bioenergy recovery [13]. The present study also confirms its bifunctional performance as both the MFCs could remove almost $90 \%$ of the COD from 
fish market wastewater. In contrast, the COD removal efficiencies of $92 \pm 4 \%$ and $90 \pm$ $3 \%$ were obtained in MFC-1 and MFC-2, respectively, with an excellent coulombic efficiencies of $55 \pm 3 \%$ and $50 \pm 2 \%$, respectively (Figure $3 \mathrm{~b}$ ). The results obtained from MFC using $\mathrm{Cu}-\mathrm{Sn}$, however is not significantly higher as compared to the MFC using Pt$\mathrm{C}$, but the cost of power production was found to be 33-times lower in MFC-1 compared to MFC-2, which reveals the promising applicability of $\mathrm{Cu}-\mathrm{Sn}$ to fabricate larger MFCs for field trials.

\section{Conclusion}

The present research demonstrated successful synthesis and application of extremely low-cost $\mathrm{Cu}-\mathrm{Sn}$ bimetallic alloy. Different in-depth electrochemical analyses revealed similar ORR activity of $\mathrm{Cu}-\mathrm{Sn}$ as compared to commercially available Pt-C, which further offered excellent real-time application in MFC by assisting to recover slightly higher current at high coulombic efficiency ( $55 \%$ vs. $50 \%)$ than Pt-C catalyst at rationally low-cost (33 times lower than Pt). Therefore, it would be imperative to state that the $\mathrm{Cu}$-Sn catalyst have potential to place it on top level among different low-cost electrochemical catalysts used for ORR in MFC.

\section{Acknowledgement}

The grant from Department of Science and Technology, Govt. of India (File No. DST/TSG/NTS2015/99) to perform this research is duly acknowledged.

\section{References}

1. H. Liu, R. Ramnarayanan and B.E. Logan, Environ. Sci. Technol. 38, 2281-2285 (2004).

2. M.T. Noori, M.M. Ghangrekar, A. Mitra and C.K. Mukherjee, Proceedings of the First International Conference on Recent Advances in Bioenergy Research, $1^{\text {st }}$ ed. (Springer, India, 2016) p. 285-294.

3. M.T. Noori, M.M. Ghangrekar and C.K. Mukherjee, Int. J. Hydrogen Energy 41, 3638-3645 (2016).

4. X. Zhang, K. Li, P. Yan, Z. Liu and L. Pu, Bioresour. Technol. 187, 299-304 (2015).

5. B.R. Tiwari, M.T. Noori and Ghangrekar, Int. J. of Hydrogen Energy 42, 23085-23094 (2017).

6. C. Song and J. Zhang, PEM Fuel Cell Electrocatalysts and Catalyst Layers: Fundamentals and Applications, $1^{\text {st }}$ ed. (Springer-Verlag London, 2008) p. 1-92.

7. Z. Yan, M. Wang, J. Liu, R. Liu and Zhao, Electrochim. Acta 141, 331-339 (2014).

8. A.Y. Cetinkaya, O.K. Ozdemir, E. Koroglu, A. Hasimoglu, and B. Ozkaya, Bioresour. Technol. 195, 188-193 (2015).

9. P.N. Venkatesan and S. Dharmalingam, Mater. Renew. Sustain. Energy 5, 1-9 (2016).

10. M.T. Noori, C.K. Mukherjee and M.M Ghangrekar, Electrochim. Acta 228, 513-521 (2017).

11. APHA, AWWA, WEF, Standard methods for the examination of water and wastewater, $20^{\text {th }} \mathrm{ed}$. (American Public Health Association, American Water Works Association, Water Environment Federation, Washington DC. USA, 1998).

12. S. Cho, D.H. Shin, Z. Yin, C. Lee, S.Y. Park, J. Yoo, Y. Piao and Y.S. Kim, Chem. Eur. J. 21, 6690-6694 (2015).

13. M.T. Noori, S.C. Jain, M.M. Ghangrekar and C.K. Mukherjee, Bioresour. Technol. 220, 183189 (2016).

14. Y.Y. Chang, H.Z. Zhao, C. Zhong, A. Xue, Russ. J. Electrochem, 50, 885-890 (2014). 